\title{
El concepto del cuerpo y la persona entre los q'eros de la Cordillera Vilcanota, Perú ${ }^{1}$
}

\author{
Anna Przytomska-La Civita
}

\begin{abstract}
Resumen
El artículo presenta la introducción a la ontología q’ero y aborda los temas ontológicos más importantes como: persona, cuerpo, salud y enfermedad. El análisis detallado del concepto del cuerpo en q'eros le permite mostrar las diferencias entre animu y samay y mostrar que deben definirse como elementos materiales (corporales) aunque sean invisibles. Se considera también cuestiones como la salud y la enfermedad mostrando su amplio significado (individual, colectivo, cosmológico) y mostrando cómo una persona está envuelta en una amplia red de relaciones $y$ dependencias entre diferentes seres (humanos o no humanos) que forman un conjunto social.
\end{abstract}

Palabras claves: cuerpo, persona, salud, enfermedad, q'eros, ontología

\section{Abstract \\ BODY AND PERSON CONCEPT: INTRODUCTION TO THE Q'EROS ONTOLOGY FROM THE VIL- CANOTA MOUNTAIN RANGE, PERU}

The article presents the introduction to Q'eros ontology and addresses the most important ontological topics such as: person, body, health and disease. Detailed analysis of the concept of the body in q'eros ontology allows us to show the differences between animu and samay and show that they should be defined as material (body) elements even if they are invisible. It also considers issues such as health and disease by presenting its broad meaning (individual, collective, cosmological) and showing how a person is involved in a wide network of relationships and dependencies between different beings (human or non-human) who form a social whole.

Keywords: body, person, health, disease, q'eros, ontology

Frank M. Meddens - Anna Przytomska-La Civita, Universidad de Adam Mickiewicz en Poznań 


\section{Introducción}

El concepto de persona está estrechamente conectado con el concepto del cuerpo. Los individuos son construidos, transformados y desintegrados a través de diferentes prácticas sociales desde el nacimiento hasta la muerte. Ser persona se asocia con mayor frecuencia con el cambio permanente, y las transformaciones claves en la condición de una persona a menudo están marcadas por ritos de paso y otros eventos importantes. Las obras antropológicas argumentan que en muchas culturas la persona no es exclusivamente autónoma, indivisible o individual. En cambio, la identidad de un individuo se percibe como relacional, es decir, es construida y transformada a través de relaciones con los demás. Por otra parte, la creación de la persona no sólo es el resultado de relaciones con otras personas, sino también con los objetos, lugares, animales y „manifestaciones espirituales del cosmos” (Fowler 2004:4). Este paradigma relacional surgió de estudios antropológicos en Asia y Oceanía con la popularización del concepto de persona dividual. Este término fue promovido por la antropóloga británica Marilyn Strathern (1988), que desarrolló a partir de investigaciones sobre las comunidades indígenas de Melanesia, donde las personas se construyen sobre la base de relaciones de intercambio con muchas otras personas. Strathern se inspiró en la obra de McKim Marriott (1976:111) que describe la sociedad de castas de la India, donde las sustancias (sangre, alcohol, alimentos, conocimiento, dinero, etc.) se trasmiten entre cuerpos, personas y castas:

En Asia meridional las entidades no se consideran ,individuales”, es decir indivisibles, como en gran parte en el caso de la teoría social y psicológica occidental, así como el sentido común. En cambio, parece que los individuos generalmente se consideran „divididos” o „divisibles” en el sur de Asia. Para vivir, las „personas divisibles" absorben influencias materiales heterogéneas. También deben donar partículas de sus propias sustancias codificadas, residuos u otras influencias activas que puedan ser replicados en personas de diferente naturaleza de las que proceden. [...] Las personas dividuales, que deben intercambiar de esa manera, por lo tanto, son siempre compuestos de los códigos-sustancias que absorben. [traducción propia]

En este sentido, el dividuo es una persona que es el producto de los dones, pero también de la inclusión de componentes de otros seres. Como resultado, sus composiciones cambian con el tiempo porque incorporan las contribuciones de otros seres entre sí y gradualmente las personas separan sus „fichas” personales para crear otros. Esto significa que las transacciones que generan personas y relaciones crean un historial de reciprocidad secuencial. Marilyn Strathern (1988:13) en el contexto del concepto melanesio de persona escribe: „De hecho, los individuos a menudo se construyen como múltiples lugares y se componen de las relaciones que los componen. La persona singular puede ser imaginada como una auto-traducción de microcosmos social". La persona dividual se basa en el flujo constante de 
sustancias entre las personas a través de diversas transacciones sociales - intercambio conyugal, regalos e intercambio ceremonial ${ }^{2}$. Marilyn Strathern ha desarrollado el concepto de dividuo en contraste con el concepto occidental de la persona individual y autónoma. Obras posteriores (Battaglia 1995, Carrithers et al. 1985, LiPuma 1998, Fowler 2004, Murray 1993) mostraron que la persona en la cultura occidental no sólo es autónoma e inmutable, sino que también contiene las características de la relacionalidad y dividualidad. Los investigadores concluyeron que en cada sociedad la persona es tanto individual como dividual, y por lo tanto es el resultado del intercambio o flujo de sustancias, dones, conocimiento, emociones de otros etc. Con relación a esto, cabe señalar que las personas surgen de la tensión entre las características individuales y los aspectos/relaciones dividuales y se construyen y actualizan conciliando un componente con otro (LiPuma 1998:57). Sin embargo, esto no significa que el concepto de persona tenga la misma dimensión en cada grupo social o cultural. El equilibrio de lo individuo y lo dividual se distribuyen de una manera diferente, y la construcción relacional de una persona puede basarse en otros elementos, dimensiones o mecanismos ${ }^{3}$. En algunos contextos, como la Europa moderna, predominan los elementos individuales, mientras que en las comunidades más igualitarias predominan los aspectos dividuales basados en las relaciones de reciprocidad. En consecuencia, el concepto de persona es una combinación de estos dos aspectos, cuyo énfasis puede variar de una sociedad a otra.

Esta perspectiva teórica es el punto de partida para el análisis del concepto de la persona entre los q’eros, que gira en torno a sustancias corporales. El análisis de los componentes individuales del cuerpo - incluyendo el contexto en el que se revelan - nos permite entender cómo forman el cuerpo humano y el cuerpo colectivo. En consecuencia, un análisis detallado de estos elementos permite explicar hasta qué punto una persona andina es individual y dividual simultáneamente y qué constituye su individualidad y dividualidad. Entre los q’eros, la reproducción del individuo y de la sociedad se basa en el flujo de sustancias corporales, que pueden adoptar la forma de depredación o intercambio (reciprocidad). El flujo de componentes de una entidad hace que la persona andina se entienda como inestable - sus elementos individuales se reducen, pierden y se recuperan; circulan en el mundo a través del intercambio o apropiación por otro ser.

Mis reflexiones sobre el concepto andino de la persona se basan en la investigación de campo a largo plazo entre los q'eros - un grupo de quechuahablantes que habitan las tierras de la Cordillera de Vilcanota en los Andes peruanos. Su territorio está dividido en 5 comunidades (anexos): Hatun Q'eros, Marcachea, Quico, Totorani, Hapu. Se dedican a la agricultura (papa, maíz), pastoreo (alpaca, lama, oveja) así como tejido para su uso propio y la venta. Los q'eros también son conocidos por las prácticas chamánicas destinadas a garantizar su bienestar y para el mercado turístico. El clima de su territorio se caracteriza por 2 estaciones (lluviosa y seca) y el territorio por 3 zonas ecológicas (entre 1800 y $5000 \mathrm{~m}$ sobre el nivel del mar): yunga, 
qeshwa, puna; que se extienden desde la selva húmeda a los picos de las montañas cubiertas de nieve. Su economía y su vida cotidiana se basan en una relación estricta con la naturaleza entendida como un conjunto de seres personales y animados. Hasta la década de 1950, los q'eros había vivido en aislamiento cultural y geográfico de la sociedad mayoritaria. Sin embargo, en los últimos 20 años, podemos observar su creciente migración a aglomeraciones urbanas: principalmente Cusco y pueblos cercanos: Ocongate y Paucartambo. Las causas de la migración se pueden relacionar con la construcción de la carretera que facilitó la comunicación con la ciudad, pero sobre todo los factores son: deseo de mejorar las condiciones de vida (trabajo, educación para los niños) y el cambio climático (que afecta negativamente al pastoreo y agricultura). Es importante señalar la participación de los q'eros en el "turismo místico" y la creciente influencia de la Iglesia Maranatha.

El propósito de este texto es presentar el concepto de la persona en la ontología q’ero como un ser individual y dividual al mismo tiempo, basando mi análisis en un amplio contexto cultural: conceptos del cuerpo, la salud, conceptos del nacimiento y la muerte, así como algunos elementos del ethos cultural andino.

\section{El cuerpo de la persona}

Según la ontología andina, el cuerpo humano está compuesto por órganos como el corazón (sonqo), el estómago (wik'sa), los intestinos (ch'unchul), los pulmones (sorq'ankuna) y se entiende como una especie de sistema hidráulico a través del cual circulan sustancias corporales (Bastien 1985:7). Los q'eros enumeran seis sustancias básicas que se pueden dividir en visibles': huesos (tullu), grasa (wira), sangre (yawar); y semen (wawsa) de los hombres; e invisible: alma (animu) y fuerza vital $(\text { samay) })^{5}$. Entre los q'eros, como en muchos otros grupos andinos (La Riva González 2005, Ricard Lanata 2007:85, Allen 2008:56; Wisller 2009:45) todos estos aspectos son interdependientes, es decir, las sustancias espirituales ( $($ nimu) no están separadas del cuerpo (Allen 2016:431). Además, todos los elementos que componen el cuerpo humano, tanto visibles (tullu, wira, yawar) como invisibles (animu y samay), no son permanentes, es decir, pueden ser aumentados, reducidos, perdidos o recuperados. Algunos de estos elementos también están sujetos a intercambio, que se utiliza para la reproducción de personas (sangre y semen) o recursos (samay) ${ }^{6}$. En este sentido, la persona (runa) en ontología andina es inestable, permeable y dividual. En esta sección discuto los elementos invisibles del cuerpo humano - el concepto de animu y samay.

El animu y samay son términos inconsistentes para los investigadores. Algunos de ellos (Boyer 2006, Ricard Lanata 2007) creen que definen el mismo concepto: el alma. Podemos suponer que esto es el resultado de la aculturación y evangelización a largo plazo de las comunidades indígenas, que consistió en sustituir las naciones indígenas por sus equivalentes europeos. Otros investigadores distinguen el alma (animu) de la fuerza vital (samay), explicando que estos son dos conceptos 
diferentes (Allen 2008:61-62). He analizado el funcionamiento de estos conceptos en la práctica de los q'eros, siguiendo cuándo y en qué contexto se revelan en su vida diaria. Esto me llevó a las siguientes conclusiones. En primer lugar, aunque estos dos elementos pueden parecer una emanación de lo mismo - es decir, una sustancia de vida que anima al ser humano - deben definirse como conceptos separados. En segundo lugar, el animu tiene las características de la individualidad, contrariamente al samay de carácter dividual. Empecemos con el animu.

Las representaciones del animu en los Andes son heterogéneas. Hay muchas figuraciones de este concepto que difieren de un grupo regional a otro y dependen de la capacidad de pensamiento abstracto del individuo. Los q'eros comparan el animu con el doble o la miniatura de la persona o con el viento, la sombra, que se encuentra en todo el cuerpo humano, es decir, en sangre, grasa, huesos, orina, uñas y cabello. Como resultado de la enfermedad, el animu puede dejar el cuerpo del individuo a través de la parte superior de la cabeza, lo que indica la inestabilidad de la persona andina. En otras partes del departamento de Cusco, otros grupos quechuas lo comparan con 'segunda piel' (La Riva González 2005:70). Según los quechuas de Ayacucho el animu se encuentra en las entrañas y en el corazón, y según quechuas de Altiplano peruano-boliviano en el pecho (Boyer 2006). Los q'eros consideran que el animu le da a la persona un carácter individual y único, porque está conectado con la conciencia, la memoria y afecta la personalidad del individuo.

Basándome en la narrativa de los q'eros, puedo concluir que el animu humano depende del género y determina la personalidad del individuo. Esto está ilustrado por el comentario de Manuel de Quico: 'Los hombres tienen 3 animus y las mujeres 7. Las mujeres tienen más animus, por eso son tan inquietas, fuertes y discuten mucho, los hombres son más tranquilos, más quietos, más débiles'. Las mujeres a menudo son percibidas como 'locas' o 'salvajes', es decir emocionalmente inestables. Los q'eros explican que su comportamiento contencioso y explosivo está asociado con un mayor número de animus que 'hierven su sangre' dado que esta sustancia según los q’eros se encuentra en la sangre (yawar). Debido a su naturaleza y el número de animus, las mujeres se clasifican como calientes (qoñi), y los hombres como fríos (chiri). Palmira La Riva González (2005: 82) escribe que los habitantes de Surimana (provincia de Canas) también mencionan que el número de 'almas' afecta el carácter de la persona y está conectado con el género. Sin embargo, los quechuas de Surimana afirman que las mujeres tienen 7 almas, por lo que son más confiables y débiles. Los hombres que tienen sólo 3 animus son más inteligentes, más fuertes y pueden engañarlas fácilmente (en el contexto de las relaciones de pareja). En este caso, se puede concluir que, por un lado, la cantidad de animus influye en las características del carácter humano, como la astucia, la fuerza, la debilidad y por otro, afecta a la agencia humana. En este contexto, cuanto menos animus, más eficazmente una persona puede influir en los demás. Según los q'eros, la formación de animus ocurre con el desarrollo del feto en el útero. Después del parto, en el proceso de crecimiento del bebé, se vuelve cada vez más unido al cuerpo visible, 
lo que se revela por el hecho de que los huesos del bebé se están haciendo más fuertes. Esto explica por qué los q'eros - como otros quechuas (Bolin 2006; Santa María 2017, La Riva González 2013) - creen que el niño no es una persona completa. El cuerpo del infante está en proceso de formación que continúa en el tiempo. Durante el desarrollo del niño, su animu sigue siendo inestable y a menudo expuesto a la fuga. La misma situación ocurre durante el período de envejecimiento, cuando el animu del individuo es cada vez más inestable, es decir, desaparece poco a poco lo que se manifiesta por la pérdida de fuerza física ( $k a l l p a$ ) y demencia - pérdida de memoria y capacidad de concentración, problemas de comunicación, deterioro de la coordinación motora etc. El animu después de la muerte no pasa al mundo de los muertos. Se transforman en alma, o espíritu o doble del difunto. El cuerpo visible del fallecido (el cadáver) se llama aya. Es un hecho interesante que los q'eros no utilizan las palabras 'cadáver' o 'muerto' u otras expresiones sinónimas al hablar de la persona fallecida. Los q’eros, refiriéndose al difunto, siempre usan el término alma - ya no lo llaman runa, ni usan su nombre. Bruno Schlegelberger (1993:69) también señala que los q'eros el mismo término utilizan en el contexto del ritual de lavar el cuerpo de los fallecidos. Allí, la palabra alma también se aplica para describir el espíritu del muerto que está presente en la ropa del difunto. En conclusión, alma es el segundo cuerpo de una persona muerta (aya), al igual que el animu es el segundo cuerpo de un humano vivo (runa).

El animu está fuertemente asociado con el cuerpo visible. Su pérdida significa enfermedad, y un período demasiado largo de su separación del cuerpo conduce a la muerte. La pérdida de animu se asocia con mancharisqa - una enfermedad causada por el susto de algo o alguien: una persona, un sonido fuerte (trueno, un golpe, un grito) o un animal salvaje, un antepasado o kukuchi (condenado), cayéndose de un caballo; así como una reacción a bromas deliberadas y maliciosas. Los síntomas de esta enfermedad son más a menudo: palidez, debilidad, gritos nocturnos, pérdida de apetito y peso. Los enfermos que sufren de esta dolencia comen tierra y sal y lloran constantemente. Según los q'eros cuando alguien está muy asustado puede volverse loco y entonces es prácticamente imposible recuperar su animu, esa persona ya no es un runa (debido al proceso de deshumanización). Si el animu no se recupera a tiempo, esta enfermedad conduce a una muerte inevitable (Greenway 1998). La mancharisqa afecta con mayor frecuencia a los niños. Cuando la madre se da cuenta de que el niño se ha volcado, ella pone un poco de sal en su boca para protegerlo del ataque de pachamamas (tierras animadas). Luego sopla en la fontanela y la aprieta fuertemente. Estas acciones preventivas tienen por objeto evitar la fuga del animu que sale por la coronilla. Cuando el niño se asusta o cae en ausencia de adultos, entonces es necesario ir a este lugar de nuevo para enterrar un poco de sal en el sitio del evento. ¿Por qué una persona con mancharisqa comienza a lamer el suelo y la sal, por qué la madre del niño le da sal preventivamente en la boca o la entierra en el lugar donde cayó el niño? Uno de los elementos importantes de la salud es el equilibrio de propiedades calientes y frías, que caracterizan cada ser existente ${ }^{7}$. 
La caída y fuga de animu significa la pérdida del elemento caliente, y por lo tanto la pérdida de fuerza física. Debido al hecho de que la sal de roca tiene propiedades calientes, se utiliza para restaurar el equilibrio del cuerpo. La sal también sirve para detener el animu en el cuerpo, razón por la cual la madre del niño espolvorea sal en el lugar donde cayó. Bernhard Wörrle (1999:183-184) escribe:

La oposición de la sal a lo no-humano, lo salvaje, lo inculto y lo antisocial, repercute también en otra dirección: así como la conducta “salvaje” de los que atentan contra las normas fundamentales del código cultural ahuyenta la sal; también con la sal, a la inversa, se puede ahuyentar lo salvaje. Por tal razón, en gran parte de América Latina se considera a la sal como un remedio apropiado para protegerse contra espíritus y otros seres que están en contacto con la esfera no-humana.

Además del uso de la sal como sustancia cargada de subjetividad humana, el tratamiento del susto consiste en la invocación del animu (animu waqay) del enfermo, que es llevado a cabo por un chamán (en los q’eros llamado paqo). El especialista sopla humo del tabaco en la coronilla de paciente, luego pronuncia alto y firmemente las palabras de invocación: 'hanpuy, hanpuy animu [ven, ven alma]'. Vicente Torres Lezama (2017:34) describe un ritual waqay animu de un niño realizado en los q'eros (comunidad Marcachea), durante el cual el chamán pronunció la siguiente fórmula: 'hanpuy, hanpuy, kaypin, kashan ñiñuyki/ vamos, aquí está tu pecho'. Según Torres Lezama, este tipo de invocación está relacionada con el hecho de que la eficacia de este ritual depende del poder de las palabras y de si serán convincentes para animu. También vale la pena señalar que esta invocación ilustra que el animu tiene voluntad propia y agencia, lo que indica sus características personales. Otra pregunta surge aquí: ¿por qué el chamán menciona los pechos al llamar el animu del niño enfermo? ¿Tal forma de invocación es simplemente un procedimiento estilístico o podemos leer algo más? Teniendo en cuenta que el animu es entendido por los q'eros como el doble, podemos asumir que el animu del niño también tiene una forma infantil y extraña la comida de la madre durante su separación del cuerpo - por lo tanto, la mención del pecho femenino puede servir como argumento para convencerlo de que regrese. La mancharisqa es una enfermedad que refleja el concepto andino de la persona, revelando su divisibilidad e inestabilidad. Los q'eros creen que los niños son más propensos a estar expuestos a esta enfermedad dado que su animu aún no está firmemente fijado en el cuerpo. Como explica La Riva González (2005:76), esto se debe a que su fontanela aún no es dura. Esta enfermedad es igualmente común para los ancianos, porque como mencioné antes, el 'alma' con la edad es cada vez más reacia al cuerpo. Además, si escapa, se hace cada vez más difícil convocarla. Los quechuas creen que asustar a una persona mayor es un acto muy indigno, ya que el proceso de tratar a los ancianos es más lento y complicado, porque su animu no quiere volver al cuerpo.

El animu puede dejar el cuerpo de una persona también como resultado de ser apropiado o robado por otros seres personales. Señalemos nuestra atención a la 
enfermedad de hallpa hap'isqa que es causada por el robo del animu por pachamamas. En este caso, el tratamiento consiste en persuadir a los agresores para que devuelvan el 'alma' robada. El chamán (paqo) lo realiza por medio del ritual haywakuy, que se basa en el esquema de reciprocidad. A cambio de alimentar a la pachamama hambrienta a través de un ritual de ofrenda, suelta la sustancia robada. En conclusión, la recuperación del animu consiste en persuadirlo para que regrese (si escapó por su cuenta) o en recuperarlo (en caso de robo). Este proceso requiere ciertas actividades rituales llevadas a cabo por un especialista ritual (paqo), porque el animu que ha dejado el cuerpo en circunstancias perturbadoras no puede encontrar su camino de regreso de forma independiente. Si no se llevan a cabo actos rituales para restaurar el animu robado, el hombre muere y su animu queda usurpado por seres no-humanos, que por lo tanto amplían sus recursos.

Según los q'eros también los animales y las plantas tienen animu. El animu de las plantas se da a conocer en varias situaciones cotidianas. Los q'eros afirman que cuando los árboles son talados, se puede escuchar un sonido, que es la voz de su animu. Otros ejemplos incluyen plagas o cultivos infértiles de papas o maíz. Las malas cosechas pueden ser causados por la pérdida del alma por la planta debido al susto del trueno y el granizo. Por esta razón la figura de arariwa - el guardián que protege las tierras de cultivo de las tormentas y truenos durante la temporada de lluvias - es tan importante en las comunidades andinas. Esto se debe al hecho de que el alma de las plantas puede escapar al asustarse de la tormenta, sufriendo así de mancharisqa (susto). Cuando llega la tormenta y la planta pierde su animu como resultado del susto, arariwa debe realizar un ritual curativo para restaurar el alma de las plantas cultivadas. De lo contrario, la planta morirá (marchitará). Por lo tanto, podemos ver que en este contexto la corporalidad de los seres humanos y las plantas es similar.

Hay una serie de ideas sobre el animu humano, que se traducen en el comportamiento práctico de los habitantes de la Cordillera de Vilcanota. Por ejemplo, está prohibido caminar y mirar hacia atrás. Los q’eros afirman que al caminar hacia atrás un hombre puede ver su animu. Tal imagen también se encuentra en otras partes de los Andes peruanos. Francisco Carranca Romero (2005) escribe que jayni (el equivalente al animu en la región de Ancash) se localiza en la espalda. Si una persona se da la vuelta abruptamente puede ver su 'alma', lo que puede resultar peligroso para el equilibrio mental. Un hombre que se asuste su alma o choque con ella puede enfermarse, volverse loco o morir. La posibilidad de ver y tropezar con el animu puede indicar que es hasta cierto punto material. Curiosamente, el animu puede tomar una forma corporal. Puede materializarse en forma de mariposa, larvas, moscas, aves. Este concepto se revela, por ejemplo, en la historia de Víctor de Quico sobre el 'viaje espiritual' de un chamán y la transformación del animu en animales.

Altomesayoq decían que antes viajaban como cóndores o pumas u otros animales. En los viejos tiempos altomesayoq lo hacían. [...] Luego regresaban, después de 
unos días, 7 días. Decían que llevaban su animu a este lugar o a tal pueblo, que comían juntos, que comían unas cosas ricas con los apus. [...] Estaba en dos lugares al mismo tiempo, fue hace mucho tiempo. Ahora ya no. (Víctor de Quico)

Este fragmento demuestra que altomesayoq (chamán) puede estar en dos lugares a la vez - su cuerpo visible en la aldea, mientras que su cuerpo invisible (animu) está en un viaje donde come con seres no-humanos (apus). Víctor me explicó que, en estos casos, uno de los animus viaja bajo la forma material (de un animal). Esto demuestra que el chamán puede estar en dos lugares al mismo tiempo. El material etnográfico que he recogido no me permite evaluar claramente si este concepto está relacionado con la transformación o adopción de la forma animal, o si consiste en la invasión de animu del chamán al cuerpo de un animal (posesión) y apoderamiento de él. Sin embargo, cabe señalar que esta situación no es cotidiana ni accesible para todos. Según Víctor, el viaje del animu en forma de un animal sólo está disponible para chamanes poderosos (altomesayoq) y, como señala, hoy los chamanes q'eros no practican este tipo de viajes, porque ya no son tan poderosos como solían ser en el pasado. Además, el viaje de animu es una condición muy peligrosa. El cuerpo visible y el animu no pueden separarse durante mucho tiempo, ya que esto puede resultar en una enfermedad o la muerte.

Otros estudios andinos nos proporcionan información sobre el viaje de animu durante el sueño. La realidad onírica es entendida por los quechuas como una realidad paralela (otro mundo) que ocurre simultáneamente. Después de conciliar el sueño, el animu sale por la boca (Cáceres Olazo 1970:26; La Riva González 2005:79-80) y emprende un viaje. El resultado de esta travesía son sueños entendidos como recuerdos de su doble. Cuando el animu participa en muchas actividades durante el viaje, en consecuencia, la persona tiene una sensación de fatiga después de despertarse, incluso a pesar de muchas horas de descanso. Una vez más, esto ilustra la dimensión real de las experiencias del animu. El sueño - que para nosotros es una creación fisiológica, un reflejo de la realidad subconsciente (no despierta) o vacía (Riches 1995:112, para Willerslev 2007:176) - los q’eros ven como una experiencia verdadera y consciente del animu, que tiene un impacto directo en la vida del individuo. René Willerslev explica que en el caso de las comunidades animistas siberianas (Yukaguiros), la diferencia en el concepto de sueño tiene sus raíces en las suposiciones ontológicas básicas. Sigmund Freud, como muchos otros filósofos occidentales, asumió que la mente humana está separada del mundo, razón por la cual creen que los sueños reflejan sólo el estado interno del individuo. En el caso de los Yukaguiros (pero también otras comunidades animistas), la mente está directamente relacionada con la condición de la persona en el mundo, ya sea despierta o dormida. En este sentido, una persona siempre existe conscientemente en un mundo con el que tiene una relación constante (Ingold 2000:101).

Como ya hemos mencionado el animu - como la sombra o el doble de cuerpo humano - es de alguna manera material, por lo que los q'eros afirman que 
se puede colisionar con ella. Otra manifestación de su materialidad o fisicidad se asocia con la creencia de que el tamaño del animu es pequeño, por lo tanto, puede convertirse (o entrar) sólo en animales pequeños: gorrión (pichinku), colibrí (k’enti) y mariposas (pillpi). Aunque el animu es de alguna manera material en su mayoría es invisible. La invisibilidad no significa en la ontología q’ero intangibilidad, sino inaccesibilidad al ojo humano. La Riva González (2005:64) escribe sobre este problema epistemológico en el contexto de otro grupo quechua (Surimana):

Estrechamente asociada a otras sustancias vitales, el animu es una entidad corporal compleja, inmaterial y material a la vez, que ha ido amalgamando e incorporando características y funciones de antiguas entidades corporales anímicas precolombinas e hispánicas como el camac, el sungu, el anima y, las almas, encontrándose también relacionada con otras sustancias o entidades corporales como la sangre, la sombra, el nombre de la persona, entre otras [...].

Aunque no he registrado ninguna representación material de animu humano entre los q'eros, en otras partes del departamento de Cusco podemos encontrar miniaturas humanas que personifican el animu. Las muñecas de los bailarines pabluchas (también llamados Pablitos o Ukukus) que participan en la peregrinación al santuario de Qoyllur Rit'i, son entendidas como su animus. Pablucha es una figura que representa a medio hombre, medio oso, cuyo papel es mantener el orden durante la peregrinación y la celebración que lo acompaña. Cuando los bailarines se ponen las máscaras, empiezan a hablar con un chirrido falso - piden comida, por ejemplo, „Lucito tiene hambre” - que representa la voz de su animu. Cuando Pabluchas paran los bailes, ponen sus muñecas en un círculo para que ellos también puedan alimentarse y descansar (Valencia 2013:11).

A su vez, el término samay (también sami) está representado con mayor frecuencia por aliento o soplo y se entiende como una fuerza vital o una sustancia animadora. Los quechuas creen que todos los seres (humanos, animales, plantas, fenómenos atmosféricos, minerales etc.) tienen samay. La investigadora estadounidense Catherine Allen (2008: 253) escribe:

La circulación del sami o fuerza vital, subyace a todas actividades culturales, desde los rituales religiosos hasta las actividades políticas o económicas. Desde este punto de vista, todas las cosas existentes (personas, llamas, montañas, chacras de papas, casas, lo que sea) están imbuidas de vida. La fuerza vital puede transferirse de un ser viviente a otro. El flujo en sami depende del mediador material. En el universo andino no existen esencias sin cuerpo. En esto, el sami recuerda mana polinesiense y a nuestro concepto de energía. El flujo en sí es neutro y debe ser controlado y dirigido de manera que todas las cosas alcancen su propio modo y el grado de vivacidad. Toda la actividad gira alrededor de este problema central: controlar y dirigir el flujo de la vida.

El samay puede parecer similar al concepto del animu, hasta el punto de que algunos investigadores creen que es el mismo concepto. Ambas propiedades 
son invisibles y se definen como un viento o soplo. Al mismo tiempo, son elementos que animan al hombre y le dan la agencia. Durante mi trabajo del campo estuve observando algunos hechos que sugieren que los q'eros entienden el animu y el samay como propiedades distintas. A continuación, voy a tratar de esbozar algunas sutilezas asociadas con ello.

Según los q’eros, el samay circula entre todos los seres animados y subjetivos del mundo (humanos, muertos, montañas, lagos, ríos, animales, etc.) y permite el contacto y la comunicación entre ellos. Según Gerald Taylor (2000) y Frank Salomon (1991), la palabra samay proviene de la palabra camay y se refiere al proceso de influir o afectar a alguien o algo (Gonzalez Holguin 1989 [1608]:76; za La Riva González 2005: 66). El concepto de camay se encuentra en numerosas historias andinos precolombinas de los siglos XVI y XVII sobre héroes míticos - Pariacaca, Pachacamac y otros, que tratan sobre el papel pedagógico de héroes míticos y la relación simbólica entre estos personajes y la „naturaleza personal”. Aprendemos de ellos que estos héroes míticos poseían casca, camac o callpa (Celestino 1997). Estos términos se refieren a la fuerza vital que anima al mundo. En los mitos, esta energía animadora es transmitida por antepasados y héroes míticos a los seres humanos y otros seres animados (no-humanos). Como escribe Olinda Celestino, cada uno de estos héroes míticos tenía diferentes grados de capacidad de animar, es decir „dar la vida”. Además, algunos especialistas podían acumular el camac proveniente de varios héroes míticos, convirtiéndose así en un camaca ancha, es decir, poderoso. Como resultado, adquirían también la capacidad de animar. Tales especialistas eran chamanes, curanderos, clarividentes o hechiceros. En los mitos andinos, los héroes culturales transmitían a la gente las habilidades, costumbres, rituales y normas que la gente debía seguir.

Basándome en el análisis de las narraciones y rituales q’eros, entendí que el término samay siempre se utiliza en el contexto del contacto con otras personas nohumanas (coca, apus, pachamamas). Además, este concepto se revela en prácticas rituales donde las personas que interactúan con no-humanos (apus, pachamamas, muertos) tienen que ser identificados. El samay es la esencia de la vida, que circula en la pacha (universo, tiempo-espacio) y es compartida por los diversos seres que la habitan. Los rituales andinos son realizados por los chamanes con el fin de mantener, restaurar y controlar el flujo de samay o dirigirlo a alguien. En este contexto, el samay asume el carácter de la fuerza vital que se revela en acción - en los rituales de samincha, challay, pukllay, kuka qhaway y haywakuy. Vale la pena señalar que en todos estos casos esta sustancia también se revela a través de movimiento - en el soplo, en el vapor que flota hacia arriba, en una bebida vertida en el suelo, etc. Los rituales en los que samay está presente consisten en la comunicación y las interacciones entre personas humanas y no-humanas. Por ejemplo, durante la práctica diagnóstica de la lectura de hojas de coca (kuka qhaway), el chamán (paqo) le pide al paciente que sople 3 veces en las hojas de coca, y por lo tanto la persona pasa 
su samay. Los investigadores interpretan el acto de soplar con mayor frecuencia como una invocación (Sánchez-Parga 1985:317; Wagner 1976:200) o como acto de comunicación (Urbano 1976:9) con otros seres personales. Mi investigación revela otro aspecto de este fenómeno. En una ocasión, paqo Nicolás, mientras realizaba el kuka qhaway, me dijo: „Ya te tengo, tengo tu samay”. Me explicó que, en el aliento de la persona, se localiza samay, el cual contiene su información personal (sobre su pasado, presente y en parte sobre el futuro). La coca recibe información sobre el remitente a través de su aliento junto con las peticiones contenidas en la invocación (waqay) expresada por el chamán. El samay y su invocación son transferidos a las montañas (apus), siendo seres personales que ayudan al chamán en el proceso de diagnóstico. Los q'eros señalan que el samay es un elemento muy importante de este ritual, de lo contrario se podría comparar este acto con una carta sin remitente. Sin el samay los apus, no saben de quién viene la pregunta y a quién hay que responder. El soplo (aliento) se puede entender aquí como un medio de transporte de samay o samay en sí mismo que sirve para comunicarse con no-humanos, como un modo de comunicación no verbal. También cabe señalar que en el contexto de kuka qhaway el samay se separa del cuerpo humano y se transmite a otros seres con fines diagnósticos. En este contexto, representa el cuerpo humano o es su multiplicación temporal, porque la imagen del cuerpo humano se revela en las hojas de coca durante la lectura diagnostica. Lo que sucede con el samay durante el ritual kuka qhaway se puede observar durante otras prácticas rituales andinas. En los Andes peruanos podemos observar una analogía entre las piedras zoomórficas (illas), la coca, el altar del chamán y las ofrendas (haywakuy). El mismo mecanismo se puede encontrar en forma de huevo y conejillo de indias utilizado para rituales diagnósticos en los Andes ecuatorianos. Todos estos objetos son de hecho seres personales que durante el ritual constituyen la miniatura que reproduce el otro ser en sus diversas escalas $\mathrm{y}$ formas (paciente, $a p u$, universo). A través de samay la persona se multiplica temporalmente en miniaturas (coca, altar, conejillo de indias, huevo) - que con fines de diagnosis o curación se convierten en la materialización del cuerpo del paciente. La relación entre la miniatura y la totalidad es bidireccional, lo que cambia en la miniatura transforma la totalidad y viceversa. Esto lleva a la conclusión de que la persona en ontología andina no solo es partible pero también distribuida. El concepto 'distributed persond' fue desarrollado por Alfred Gell (1998) en el contexto de las obras de arte, definiendo el fenómeno en el que las obras de arte son persuasivas con la subjetividad de sus creadores, sin dejar de ser seres separados. En el contexto andino, este concepto fue utilizado para describir la relación entre illas (piedras de poder) y apus por C. Allen (2016). Sin embargo, este concepto también se aplica en muchos de los otros contextos enumerados anteriormente. La divisibilidad de una persona se refiere a sustancias corporales (visibles e invisibles) que pueden ser desconectadas y divididas, y la dispersión se refiere a la posibilidad de su multiplicación temporal en otros objetos. 
He observado que esta sustancia está presente también en las ofrendas entendidas por los q'eros como un acto de alimentación de los no-humanos (apus y pachamamas), que se basa en el patrón de ayni, es decir la reciprocidad (alimentación mutua). Como ejemplo puede servirnos el challay, un ritual andino para compartir comida con seres no-humanos (Harrison 1989:94, Valderrama, Escalante 2012). El challay como un acto de alimentación de los no-humanos implica dejar caer unas gotas de bebida en el suelo que contienen el samay o salpicar hacia los apus. Catherine Allen (2008:56) escribe que los quechuas de Colquepata creen que la circulación del samay también está presente al cocinar comidas. En el aroma de la comida, en el vapor o en las burbujas hay samay, que flota en la dirección del apus. A cambio del sacrificio (alimento que contiene samay) los no-humanos devuelven a los humanos en forma de buenas cosechas y fertilidad de los animales. En este contexto, el samay no sólo es una multiplicación del cuerpo del individuo, sino también objeto de intercambios entre humanos y no-humanos.

El samay es una sustancia que se puede reducir o acumular, lo que se asocia con el estado de poder o eficacia de una persona. Esta energía vital puede perderse como resultado de las acciones de hechiceros o las personas no-humanas (como el arco iris, saqra, serpientes, pachamama hambrienta). El robo de samay se expresa por las frases 'te chupó' o 'te comió' (mijurapun) - que se refiere a la apropiación de la fuerza vital de la víctima. En los Andes ecuatorianos, el concepto de fuerza vital se asocia con faja, un cinturón andino, hecho de lana de llama usado como soporte para la columna vertebral durante el trabajo físico duro (incluyendo cargas pesadas), pero también para protegerse contra la pérdida del samay. Al mismo tiempo, es utilizado por los chamanes ecuatorianos (yachak) en sus rituales. En este caso, los protege de la pérdida de poder, y durante los rituales de curación simultáneamente lo proporciona. La faja andina mide unos dos metros de largo y se la coloca en la pansa cubriendo el ombligo, que es un punto crítico del cuerpo humano. Los quechuas ecuatorianos creen que el ombligo es el centro del cuerpo y un punto simbólico del universo y por lo tanto más vulnerable a los peligros externos. En la cultura andina los objetos como la sal, el cinturón de lana y el ají representan el orden humano y la negación de la subjetividad no-humana, por lo tanto desempeñan una función protectora (Moliné Fioravanti 1991a, 1991b). La pérdida o el robo del animu y samay que salen a través de la boca, la punta de la cabeza o el ombligo demuestran la inestabilidad del cuerpo. En muchas comunidades, en las cuales los cuerpos son permeables, existen las prácticas que tienen por efecto evitar que las sustancias corporales escapen. Por ejemplo, se cubre el cuerpo con ropa, o se tapa las aberturas corporales especificas e incluso se aplica los tatuajes (cf. Rasmussen 1995, Gell 1993).

Discutamos brevemente los otros elementos corporales. La sangre (yawar) es una sustancia asociada con la vitalidad de la persona que circula por el cuerpo, el cual se entiende como un sistema hidráulico (Bastien 1985). Según los q’eros, la 
cantidad de la sangre en el cuerpo es limitada, es decir, si se pierde, su recuperación no es posible. Este concepto hace que las comunidades andinas sean muy reacias a extraer sangre. La grasa (wira) se asocia con el concepto de energía y productividad. Esta sustancia es muy importante para la supervivencia en el clima de montaña frío, ya que hay muy pocas fuentes de calor externas. Una persona enferma es una persona delgada, $y$ una persona de cuerpo grueso es considerada en los Andes como una persona fuerte y saludable. La grasa es una sustancia almacenada en el cuerpo. Si se pierde, por ejemplo, como resultado de una enfermedad o un ataque de pishtaco (una criatura que roba grasa humana) - su cantidad puede ser renovada. Aunque hay algunas diferencias regionales entre las diferentes sustancias, se puede concluir que las comunidades andinas entienden el cuerpo como un conjunto de procesos orgánicos y respiratorios que son responsables de la circulación de sustancias físicas, tanto visibles como invisibles.

\section{Formación de la persona (runa)}

En esta sección, analizo el concepto de persona entre los q'eros desde la perspectiva procesual y constructivista, en el sentido de que me enfoco en el proceso de formación de la persona. A este respecto, presto especial atención a qué sustancias corporales se utilizan para la creación de la persona y qué seres personales están involucrados en este proceso. Estudio también las prácticas rituales a través de las cuales se construye una persona. La formación de un runa comienza en el útero, donde el niño se crea a partir de la sustancia de ambos padres - la sangre menstrual de la madre y el esperma del padre. Con el desarrollo del cuerpo del niño, también se forma su animu, que es visto como una copia o sombra de él. En los Andes, el embarazo se entiende como una condición médica, y el feto es visto como una especie de parásito (depredador), que se alimenta de la sangre de la madre anfitriona (Santa María 2017, Hubí 1954: 77, Burgos 1995:89, Bolton 1976:72). Esto nos lleva a la conclusión de que la nueva vida surge de un acto de depredación (alimentarse de la sustancia constitutiva de la madre sin dar nada a cambio), que durante el crecimiento y desarrollo social se transforma en ser con el mayor grado de cercanía y familiaridad (parentesco). Según los qeeros recién 8 días después del nacimiento el bebé se convierte en una persona. Esta condición se entiende como un período de transición durante el cual el niño no es ni un feto ni un ser humano. Cabe señalar que en la cultura andina - así como muchas otras culturas indígenas - un niño se entiende como una persona incompleta que toma la forma completa de un runa en el proceso de socialización.

Durante el embarazo la sangre de la madre, de que se alimenta el feto, se calienta. Por lo tanto, la pérdida de sustancia conduce a un desequilibrio corporal de la mujer embarazada. En consecuencia, durante este período la mujer está expuesta a ataques de no-humanos depredadores y a la pérdida de animu (mancharisqa). Si 
una mujer embarazada sufrió el ataque de un ser maligno (por ejemplo, mal viento), el chamán (paqo) realiza un ritual de limpieza utilizando la ruda y otras plantas, fuego y vela negra para asustar a los seres depredadores y recuperar el animu robado. En caso de complicaciones del embarazo se realiza la ofrenda ritual (haywakuy) pidiendo apus y pachamamas el nacimiento de un descendiente sano y fuerte. El bebé nace en casa con la ayuda de una partera (wachachiq) o un miembro de la familia que sabe asistir en el parto. Hay muchas obras etnográficas que describen cómo las parteras u obstetras reconocen el sexo del feto. Las ideas sobre estas prácticas indican diferencias de género. En Junín se cree que el embarazo del niño dura 9 meses, el embarazo de la niña puede durar un mes menos (Hubí 1954: 78, Burgos 1995:104). En la región de Cusco se cree que el feto de la niña se desarrolla en 3 meses y tiene 7 animus. Los chicos son creados dentro de 6 meses y tienen 3 animus. El parto es una situación peligrosa para la madre, ya que la sangre evoca seres depredadores (por ejemplo, $s a$ qras o wayras). En diciembre de 2015, el primer hijo de Marco y Daniela nació en Marcachea. El chamán y obstetra Florentino, me explicó que era necesario incensar la cabaña con una mezcla de hierbas para protegerse del uraña wayra (viento de montaña) y soq'a wayra (viento de antepasados), lo que puede enfermar al bebé y a la madre. Florentino y María, la madre de Marco, también realizaron un ritual phukuy (soplo ritual), dirigiéndose los pachamamas pidiéndolas un parto rápido y el nacimiento de un bebé sano. Daniela daba a luz toda la noche, el nacimiento fue largo y doloroso. La suegra masajeaba suavemente el abdomen de la parturienta, frotándolo con qoll$p a$ (sulfato de hierro o cobre), que los q'eros recogen en las laderas de las montañas. Después del nacimiento, al bebé también se frota con qollpa, con objetivo de proteger contra seres depredadores. Un lugar muy importante después del parto ocupa la placenta (thami o llaphllawa). Es necesario lavarla minuciosamente y luego quemarla en una fogata $o$ en brasa. La ceniza que se genera al quemar la placenta se mezcla con una infusión de hierbas o agua caliente y se administra a la mujer. Florentino me explicó cuál es el propósito de esta práctica:

Hay que quemar la placenta, sino la madre se va a enfermar, tienes que tirarla al fuego, no puedes tirarla así no más. Si lo tiramos al rio, la madre se va a enfermar. $\mathrm{Y}$ este polvo [placenta quemada] la madre tiene que comer sino se enferma. Eso sale vivo, por eso tienes que quemarlo. Está vivo cuando lo quemamos, así muere entonces. Siempre hay que beber con un poco con una infusión. Para más fuerza, cuando [las mujeres] no la beben después del parto, se desmayan, es difícil para ellas. Y entonces el resto de esta ceniza con cordón umbilical hay que enterrado en la brasa.

En la cultura andina, la placenta no es sólo un ser vivo y personal, sino también una especie de doble análogo (simpático) del niño. Como he mencionado una de las prácticas muy importantes es lavar bien la placenta antes de quemarla. Se cree que cuando un niño camina sucio o tiene algunos defectos físicos, se asocia con lavado inadecuado o daño a la placenta. Los aimaras explican el alcoholismo por el 
hecho de que varias gotas de alcohol cayeron sobre la placenta (Carter y Mamani 1982:145; Martinez y Mari 1976:122). Arrojar una placenta a un río, sin quemarla, puede causar enfermedades del niño y la madre, e incluso su muerte (Llanos Cervantes 1992). Los q'eros creen que la placenta no quemada puede ser peligrosa para la vida de la parturienta, porque puede tratar de volver al cuerpo de la madre. Para evitar esto, los q'eros la queman 'para que muera'. La mujer come un poco de placenta quemada, que se añade al té de coca u otras hierbas. Luego se realiza la ofrenda dirigida a las pachamamas locales, en la cual se entierra la placenta con productos vegetales (coca, frutos secos, granos), que se entiende como un acto de alimentar a los seres no humanos. 'No puedes enterrar la placenta sola, siempre con un producto como hojas de coca, porque de lo contrario [Pachamama] se alimentaría del bebé' me explicó María, la abuela del recién nacido. A cambio de la ofrenda, los padres piden a los no-humano por salud y felicidad para el recién nacidos.

Josef Estermann (1998) subraya la relación entre madre e hijo en la cultura andina. Los quechuas, queriendo decir 'tengo un bebé, utiliza la frase 'waway kanmi' que podríamos traducir literalmente como 'de mí es mi hijo. Según el investigador, el concepto de posesión se expresa por la relación entre seres, donde el verbo kay significa „ser” y „poseer” al mismo tiempo. El proceso de formación de una persona continúa alrededor de la edad de 1 año, cuando se desteta el niño. Llullu wawa (bebe amamantado) se convierte entonces en pukllaq wawa (niño individual). Pasar de la posición pasiva de ser alimentado (condición de dependencia y falta de responsabilidad) a la posición de comensalidad (el acto de comer las mismas sustancias junto con parientes) es una etapa muy importante en la formación del ser humano. En los Andes, alimentarse y comer juntos (comer la misma comida) es la parte muy importante de producir intimidad y afinidad, además de ser una persona (runa). En este proceso, la construcción del parentesco entre los miembros del grupo de origen y el niño continúa su proceso de convertirse en una persona completa. La comensalidad permite generar o fortalecer lazos de parentesco que garantizan la reproducción de un grupo mediante la creación las personas corporalmente iguales. En el contexto de los waris de Brasil, Aparecida Vilaça $(2002,2005)$ explica que el hecho de que la madre y el padre sean humanos no significa que el producto de su relación deba pertenecer a la misma especie. El niño puede ser concebido como 'otra cosa' (pez, pájaro, mono) y debe transformarse en un ser humano a través de ciertas prácticas a través de las cuales se construye su cuerpo: comensalidad, sentimientos maternos, aprendizaje del lenguaje, etc. En el contexto de los q'eros, el feto y el recién nacido también son percibidos como seres no-humanos, que se transforman en un runa (humano) y un pariente cercano a través de la comensalidad y otras prácticas sociales. Como señala Carlos Fausto, comer como el otro o comer junto con el otro es un fuerte vector de identidad que conduce a la identificación con la familiaridad y Otredad. En los q'eros, el comienzo de la participación en la comensalidad se asocia simultáneamente con el ritual de chukcha rutuy (corte de pelo), que es el primer 
ritual de reciprocidad en la vida humana, que incluye tanto a los seres humanos como a los no-humanos. En los q'eros este ritual se realiza en el primer año de vida del niño, cuando el animu del niño se vuelve más unido al cuerpo. El ritual de chukcha rutuy consiste en cortar el primer cabello, que es llevado a cabo por compadre o comadre quienes se convierte en una especie de tutor adicional (madrina/padrino) que establece afinidad con el niño y su familia. Tradicionalmente, este ritual se realiza dentro de la familia, con los abuelos o tíos del niño, pero hoy en día a veces este ritual va más allá de parientes cercanos. El regalo de comadre/compadre es un animal reproductor, que en el futuro pasa a formar parte de su rebaño. El cabello del niño junto con otros productos y la ofrenda para los no-humanos se entierra en las montañas en un lugar secreto. Dependiendo de lo que los padres desean para el niño, se entierra también ciertos objetos o plantas:

Enteraban el warankaysu [Ranunculus praemorsus], con esto hacían los despachos [haywakuy], para que los niños tengan las vacas. Para llamas la phallcha [Gentianella], para las chacras traina mucha papa y flores de papa. Todo para fertilidad. Para que tu niño sea paqo traían las qhuya, las piedras mágicas, enterraban con el despacho, y llevaban a un lugar secreto, muy profundo donde la gente no llegaba. A veces trepaban con las sogas y los enterraban en las cuevas. Solo los padres y padrinos sabían de eso, nadie más. (Victor de comunidad Kiko)

Este ritual se llama estrella churay (selección de estrella) e implica que el niño de aproximadamente 1 año, además de establecer una relación de comensalidad con otras personas, también inicia relaciones de reciprocidad con no-humanos. A cambio de una ofrenda para los apus locales, los padres los piden bienestar y cuidado por él. Según los q'eros, se lo realiza 'para la prosperidad, una buena vida, para que sea una buena persona'. De esta manera, el niño es elegido por un $a p u$, que se convierte en su cuidador (apu michiq). Los q'eros creen que los no-humanos a veces luchan por un niño recién nacido con el que puedan establecer relaciones de reciprocidad, porque a través de esto multiplican su poder. La mayoría de la gente no conoce su apu michiq, pero es posible comprobar esto a través del ritual de $k u k a$ qhaway realizado por paqo. A veces apu michiq también puede aparecer en los sueños. El apu michiq acompaña al hombre a lo largo de su vida hasta su muerte, a menos que esta relación se rompa, por ejemplo, al no realizar las ofrendas, lo que puede conducir a enfermedades. El propósito de este ritual es producir el bienestar del niño, que se garantiza estableciendo relaciones amistosas con los seres no-humanos, cuyo favor está garantizado por el cultivo, la salud y la fertilidad de los animales.

El proceso de formación de un runa (humano) continúa con el desarrollo del niño, a quien se le enseña runa simi (quechua, literalmente el idioma de la gente) y otros elementos de la vida social. Ya alrededor de 4-5 años los niños están incluidos en las tareas domésticas y el trabajo agrícola y pastoral de acuerdo con su género. Las niñas ayudan a las madres a pastear los animales, alimentar a los cuyes, conejos o pollos, cocinar, lavar y muchas otras actividades llevadas a cabo por las 
mujeres. Los varones ayudan a los hombres en los trabajos agrícolas, recolectar leña y en muchas otras actividades masculinas. Alrededor de los 15-18 años, los jóvenes comienzan a masticar hojas de coca, que se asocia con la madurez, la edad adulta y la disposición a formar su propia familia. También hay que añadir que en los q'eros se observa reciprocidad intergeneracional. Mientras los padres cuidan de sus hijos hasta que se crean sus propias familias, los niños están obligados a cuidar a sus padres ancianos. Tal arreglo intergeneracional es esencial para la supervivencia, ya que en comunidades agrícolas de alta montaña los ancianos no pueden contar con el cuidado del estado. Cabe señalar que la reciprocidad intergeneracional no termina con la muerte de los padres, sino que va más allá. La memoria de los muertos y rituales funerarios son los deberes de sus hijos.

El rito de paso más importante en la formación de una persona en los Andes peruanos es el matrimonio, que es principalmente un tipo de contrato social destinado a distribuir recursos y sustancias para que sean beneficiosos para ambas partes de la transacción. Los jóvenes disfrutan de la libertad sexual antes de formar una pareja formal. Eligen según su propio gusto, no se practican matrimonios arreglados. Sin embargo, la elección de la pareja debe ser aceptada por los padres de ambas partes y cumplir con los requisitos de las reglas de intercambio endogámico y matrimonial, evitando el incesto (hasta 5 generación). La formación familiar comienza con mayor frecuencia a la edad de 15-16 años. El servinakuy o uywanakuy ${ }^{8}$ (matrimonio andino) comienza cuando un hombre declara su deseo de casarse, las familias de las partes llegan a un entendimiento común y los jóvenes comienzan a vivir juntos. El matrimonio en los q'eros puede ser patrilocal o matrilocal, lo que significa que tanto la mujer como el hombre pueden cambiar su lugar de residencia uniéndose al hogar de su pareja. El primer período del matrimonio se entiende como una prueba u observación. Durante este período, la pareja puede conocerse mejor, verificar su compatibilidad y si la vida en la nueva familia cumple las expectativas. Durante esta etapa, más a menudo en el caso de que la pareja aún no tenga descendencia, la separación ocurre. Si durante el servinakuy la pareja decide separarse, parten sin consecuencias. El servinakuy es un asunto familiar que debe ser acordado entre las familias de las dos partes. La esencia del matrimonio en los Andes se basa en el principio de reciprocidad (ayni). Esto se aplica tanto a cuestiones económicas (contribuciones de ambas partes) como a cuestiones personales (habilidades y características). El propósito más importante del matrimonio es la reproducción, lo que significa que la infertilidad de uno de los cónyuges es la base para la cancelación o separación de matrimonio, ya que tal relación desde el punto de vista social no es eficiente. Aunque el matrimonio es una cuestión de libre elección entre dos partes, no se basa en las ideas del amor romántico, sino en el interés común de ambas familias. La reciprocidad de la familia va más allá de la pareja e incluye las relaciones interfamiliares (la familia extensa). Un adulto participa en el sistema ayni, que se expresa con la frase: dar para recibir. En quechua, literalmente significa retorno, 
compensación y reciprocidad, y es uno de los principios más importantes en torno a los cuales se organiza la vida social de los q'eros. En el contexto de la comunidad, el ayni es un sistema andino de asistencia mutua, intercambio y una red de responsabilidades sociales. Se revela en varios contextos de la vida social y ritual como el intercambio de alimentos, la entrega mutua de regalos, el intercambio conyugal, las funciones políticas y las prácticas rituales. Este sistema social de reciprocidad tiene como objetivo garantizar que cada individuo participe en la circulación de bienes, recursos naturales y los beneficios de la vida social y política.

\section{Dualidad y fractalidad de la persona}

La divisibilidad y dividualidad no son suficientes para describir la complejidad del concepto de la persona andina. Muchas obras dedicadas a la cultura andina indican que el hombre andino percibe el mundo ( $p a c h a)$ como su conjunto compuesto por una red de elementos interconectados (cf. Allen 2008, Rivera Palomino 1994; Estermann 1998; Descola 2013). El mundo andino se compone de elementos divisibles y difusos que son a la vez individuales y dividuales. ¿Cómo es posible establecer relaciones entre diferentes seres en un mundo tan caótico y diverso? ¿Están clasificados y agrupados de alguna manera o son una manifestación de caos? Según Philippe Descola (2013), en la ontología andina el estado del mundo es una diferencia infinitamente compleja, y la similitud es una manera de hacer este mundo más comprensible y soportable. Este mundo complicado y aparentemente caótico está ordenado por analogía ${ }^{9}$, que Descola (2013:201) considera el elemento más importante de la ontología andina (de ahí la analogía como nombre de este orden ontológico - analogismo), basado en un análisis de la comunidad aimara de Bolivia y náhuatl de México:

Con esto me refiero a un modo de identificación que divide toda la colección de seres existentes en una multiplicidad de esencias, formas y sustancias separadas por pequeñas distinciones y a veces ordenado a escala graduada para que sea posible recomponer el sistema de contrastes iniciales en una red densa de analogías que unen las propiedades intrínsecas de las entidades que se distinguen en ella. Esta forma de distribuir la diferencias y correspondencias detectables en la superficie del mundo es muy común. Por ejemplo, encuentra expresión en las correlaciones entre microcosmos y macrocosmos establecidos por la geomancia y la adivinación chinas, en la idea, común en África, que los trastornos sociales son capaces de provocar catástrofes climáticas, y también en la doctrina médica de las firmas que basan la etiología y la terapia de las enfermedades en los aparentes parecidos entre, por un lado, sustancias u objetos naturales y, por otro, síntomas y partes del cuerpo humano. Lo que inmediatamente llama la atención en tales sistemas son la inventiva desplegada con el fin de realizar un seguimiento, a efectos prácticos, de todas las similitudes y resonancias que la observación ofrece inferencia: la búsqueda del bienestar o de las causas de la desgracia se basa en la hipótesis de que los cualidades, movimientos y modificaciones estructurales de ciertos seres 
existentes ejercen una influencia en el destino de los seres humanos o están influenciados por el comportamiento de esos humanos. Esta obsesión por la analogía se convierte en una característica dominante que se afirma con un vigor que se vuelve cada vez más maníaco cuantos más sus efectos en la vida diaria tienen fama de ser cruciales.

Según Descola (2013:205), la analogía es un medio flexible y polivalente para crear similitudes que probablemente se aprovechen no sólo de la simetría, sino también de diversas formas de inversión, inclusión y división. Se suma a estos vínculos de atracción o simpatía, que se refiere a la acción a distancia, que también es metonímica (ver magia simpática). En el caso de los quechuas, la analogía es en realidad fractal. El concepto de fractalidad deriva de la teoría del caos, pero se aplica no sólo en matemáticas y geometría, sino también en antropología cultural (Dehouve 2015, 2016; de la Cadena 2015; Strathern 2004). Por el término fractalidad, me refiero a la relación de que el todo y su elemento se construyen de una manera análoga, creando una estructura de auto-similiar (ang. self-similarity) (Mosko\&Damond 2005). En otras palabras, tiende a repetir patrones o estructuras en múltiples niveles o escalas de un sistema determinado. La analogía fractal se traduce en términos y prácticas específicas que revelan las experiencias del mundo material. En el caso de las comunidades andinas, esta analogía fractal se encuentra, por ejemplo, en el concepto yanantin. Puede estar relacionado con las similitudes de relaciones o formas en términos metafóricos o metonímicos.

El cuerpo humano tiene propiedades características basadas en el principio de yanantin, es decir, dualidad complementaria según la cual todo lo que existe tiene un par. Tales pares binarios en el contexto del cuerpo humano son, por ejemplo: cálido-frío (q’oñi-chiri), hombre-mujer (warmi-qhari), arriba-abajo (hanan-ukhu), izquierda-derecha (loq'e-paña), muerte-vida (kawsay-wañuy). Además del concepto del cuerpo y de la estructura del mundo, la doble división se revela en muchos aspectos de la vida cotidiana de las comunidades andinas: el diseño del pueblo, las estaciones, el terreno, los patrones de tejido, los rituales y los objetos rituales. En los q'eros el esquema de yanantin se encuentra en aspectos intangibles como las canciones (q'ero taki) - en la estructura de canciones rituales y papeles musicales (Wissler 2009:45 $)^{10}$. En quechua yana significa „socio”, „amado” y morfema -ntin define la inclusión, la integración. Los elementos de yanantin no son mutuamente excluyentes, sino que existen en su complementariedad y forman una totalidad inseparable (Webb 2012). En este sentido, en un cierto contexto y momento, la dualidad se convierte en unidad. Los q'eros afirman que cada hombre es un warmi-qhari (macho-hembra), es decir, compuesto de sustratos femeninos y masculinos. El mismo principio se aplica a la pacha, es decir, al universo entendido como espacio-tiempo viviente - aunque popularmente se llama Pachamama (Madre Tierra) - que combina los femeninos y masculinos (Allen 2008:153, Platt 1986). La pareja complementaria qhari-wari es uno de los principios más importantes a través de los cuales los quechuas entienden el 
mundo y la sociedad (Silverblatt 1987:212), así como el individuo en sí mismo. Del mismo modo, cada elemento que construye el mundo se compone de pares complementarios y opuestos: el elemento masculino y femenino, el elemento cálido y frío, etc. Los diferentes pares complementarios se combinan o se superponen para formar una estructura lógica. Cada elemento parece unirse al otro. La tabla siguiente muestra los ejemplos de yanantin que se encuentran en los q'eros:

Tabla 1. Los ejemplos de yanantin en los q'eros

\begin{tabular}{|c|c|}
\hline LOQ'E - IZQUIERDA & PAÑA - DERECHA \\
\hline pachamama - universo & apus - montañas \\
warmi - mujer & qhari - hombre \\
alpaca - alpaca & llama - llama \\
tuta - noche & p'unchay - día \\
killa - luna & inti - sol \\
hurin - abajo & hanan - arriba \\
qocha - lago & urqu - cerros \\
paray mit'a - temporada de lluvia & chak'i mit'a - temporada seca \\
qolqe - plata & ori - oro \\
\hline
\end{tabular}

La tabla muestra, por ejemplo, pares complementarios de hanan-hurin, es decir, pares de arriba-abajo, que son elementos característicos de la organización social dual y la estructura espacial de los incas (Zuidema 1989, Urton 2003). Según este principio complementario, los pueblos incas estaban divididos en dos: hanansaya y hurinsaya. Hoy en día, los q'eros dividen sus aldeas en dos partes: lado izquierdo (ichiniku) y derecho (castilla). Por ejemplo la comunidad de Hatun Q'ero se divide en aldeas de izquierda como Qocha Moqo, Qolpa K'uchu, Charkapata y Hatun Rumiyoq y aldeas de derecha como Challmachimpana y Chuwa Chuwa (Wissler 2009: 48). Las prácticas rituales (atributos y altares rituales) también revelan pares complementarios de yanantin. Por ejemplo, en el ritual haywakuy (ofrenda) se puede distinguir la superposición de diferentes elementos: el lado izquierdo (loq'e) corresponde al warmi (elementos femeninos) y otros elementos categorizados como femeninos, el lado derecho (paña) corresponde al qhari (elementos masculinos) y todo lo que es masculino. La construcción del ritual haywakuy compuesto por diferentes productos (granos, flores, hojas de coca etc.) se basa en la estructura del cuerpo humano, que se divide en el lado izquierdo (femenino) y derecho (masculino). Según los q'eros, los rituales que no cumplen con este principio no tienen poder causativo. En el contexto andino, las interacciones de los dos elementos complementarios conducen a la sinergia y reproducción. Esto significa que el sentido de yanantin se revela en acción. La mujer (warmi) y el hombre (qhari) se encuentran en una colina durante tinkuy (encuentro ritual). Este ritual puede tomar el carácter de batallas rituales con el fin de obtener cultivos fértiles. Las víctimas y su sangre (yawar) que son productos de dichas batallas son percibidos como la ofrenda para 
pachamama. El tinkuy también puede asumir el carácter de bailes coquetos, durante los cuales jóvenes q'ero de pueblos vecinos tienen la oportunidad de conocerse. El propósito de esta reunión ritual es futuro intercambiar matrimonios y la formación de una nueva familia. El yanantin también está presente en el altar ceremonial, donde se reúnen las fuerzas de los apus y pachamamas, lo que resulta en cumplir la petición de la persona que realiza la ofrenda (por ejemplo, tratamiento o buenas cosechas etc.). Las interacciones entre estas parejas complementarias no sólo atestiguan su unidad, sino también a su acción sinérgica. Josef Estermann (1998:226) subraya otra dimensión de este concepto. En los Andes, una mujer es más propensa a relacionarse con lo que está dotado de sexualidad masculina (pastoreo), mientras que un hombre se ocupa de lo que es femenino (agricultura). El autor señala que tradicionalmente las mujeres ayudaban con el trabajo agrícola, pero nunca „abrían” la tierra y plantaban plantas (un acto de fertilización). La división de papeles también está presente en el arte de tejer, donde la mujer se dedica al tejer, y el hombre se dedica a la hiladura manual. Por lo tanto, podemos ver que la división de los roles masculinos y femeninos (sexualización de los deberes) tiene un vínculo directo con el yanantin, que se convierte en el punto de partida para la reproducción. La sexualidad como complementariedad, genera acción y causa, por lo que es la fuerza impulsora de las personas y de todo el cosmos. Curiosamente, una gran parte de las costumbres andinas - bailes, canciones, prácticas rituales - están cargadas de sexualidad dual y connotaciones sexuales. Todo esto se refiere a la idea de que lo que es dual y complementario es sinónimo de reproducción, fertilidad y vida.

\section{La muerta como continuación}

La muerte - aunque obvia y natural - en cualquier cultura o comunidad es un acontecimiento trágico y triste. En la cultura q’eros, al igual que otros grupos quechua, se entiende como una continuación. No es una grieta y un final, sino, por el contrario, un paso más en el ciclo de vida o una transición de una etapa de la vida a otra (Cáceres Chalco 2001:187). Cuando un runa muere, cambia de condición y se convierte en alma (una palabra prestada del español). En el proceso de morir el animu (el doble) es reemplazado o transformado en un alma que viaja al mundo de los muertos. El cuerpo físico (visible) del fallecido (grasa, sangre y huesos, etc.) se descompone y va a pachamama, que se compone de la misma sustancia.

¿Cuál es el viaje de alma al mundo de los muertos y cuáles son los ritos funerarios en los q'eros? Después de la muerte, es necesario lavar el cuerpo del difunto y vestirlo con la mejor ropa. Los q'eros afirman que hay que equiparlo con buenas ojotas porque tiene un largo camino por recorrer hasta llegar al mundo de los muertos que se encuentra dentro de las montañas. El cuerpo del fallecido se coloca sobre una mesa o en un pedazo de tela en el suelo, y luego se encienden las velas. La noche después de la muerte del hombre, la familia da la bienvenida a los invitados que 
quieren despedirse de los fallecidos y consolar a los familiares. Decir adiós (incluyendo la reconciliación) es una especie de deber, por esta razón la familia y los amigos de los difuntos de aldeas remotas acuden al velatorio. La gente expresa su dolor llorando o lamentando, dado que todos quieren expresar su tristeza y disculparse con el difunto. Según los q’eros el alma debe recibir el perdón de los vivos antes de marchar al mundo de los muertos. Torres Lezama (2017: 34-35) escribe:

[...] alma que antes de partir a la huk pacha o la otra vida debe de recoger sus huellas y “ancanzar el perdón” de sus congéneres. De manera que el alma-cuerpo debe ser expulsada a la otra vida mediante celebraciones que expíen sus culpas. En este hecho también es fundamental la fuerza de la palabra, porque permite al difunto un viaje exitoso; es decir la palabra es capaz hacerse realidad, de concretarse, de manera que suplicas y oraciones, y el perdón que piden las personas se hace efecto y el alma-cuerpo no tiene por qué volver a la kay pacha. Así quienes acompañan a la velada e el entierro al alma-cuerpo expresan discursos, piden perdón, oraciones, cantos, música y danza. El alma que no logra transitar completamente a la otra vida, o huk pacha, debido a sus faltas graves retorna a esta vida o kay pacha.

El velorio es uno de los elementos más importantes de funeral y proceso de morir de la persona. El hecho de que el proceso de muerte aún no haya terminado hace que esta sea una situación altamente peligrosa tanto para el fallecido como para su familia. Los familiares están obligados a cuidarlo durante toda la noche. Según los q'eros, quedarse dormido o dejar al fallecido desatendido puede tener consecuencias trágicas. Manuel Marzal escribió sobre un caso de secuestro del cuerpo de un fallecido por un supay (ser diabólico) en el pueblo de Wanqara en el departamento de Cusco (cita de Fourtané 2015: 132):

Una vez en el velorio los que velaban se durmieron. Y entonces, como el muerto en vida habia tenido el contacto con el diablo, éste entró y se llevó al cadáver y se lo llevó a su casa y allí lo hizo revivir. Y se quedó con él y el muerto no fue al lado de Dios, ni tampoco al fuego. Por esto los acompañantes en el velorio fuman, rezan y hablan toda la noche de cómo era la persona del muerto.

Según los qeros, tanto masticar coca como consumir grandes cantidades de alcohol (cañaso, chicha, cerveza) protege de la enfermedad qhayqa (el viento del fallecido) y les añade kallpa (fuerza) durante el velatorio. Otras actividades durante la velada (comida, canto, masticación de coca, alcohol) tienen como objetivo añadir la fuerza ( $k a l l p a)$ al difunto, que es necesaria durante el viaje al mundo de los muertos. La muerte es, por lo tanto, un proceso colectivo en el sentido de que el difunto necesita la presencia y las acciones específicas de los demás. Además, la muerte es un proceso que continúa con el tiempo y puede ser perturbado, por factores externos (secuestro, falta de perdón, problemas no resueltos etc.). Según los q’eros, durante 8 días después de la muerte el alma permanece entre los vivos, visitando lugares que a menudo frecuentaba durante su vida. Observemos que el mismo número aparece 
después del nacimiento del niño - durante 8 días el recién nacido aún no es humano. Esto significa que el proceso de nacimiento y muerte continúa en el tiempo y son los procesos en los cuales la persona es suspendida en un vacío ontológico. Durante 8 días después de la muerte, el fallecido recoge sus recuerdos y rastros (pelo, uñas, epidermis, etc.). Por eso, a veces sucede que la familia siente la presencia del difunto. ¿Qué le pasa al alma cuando se interrumpe el proceso de muerte y no se realizan ritos funerarios? Es una experiencia muy difícil, no sólo para los fallecidos, sino también para su familia y todo el pueblo. En tales situaciones, permanece entre los vivos, es decir en suspensión ontológica, vaga en forma de saqra o kukuchi - seres no humanos peligrosos para otras personas. Sufriendo, atormenta no sólo a su familia, sino que perjudica a todos los habitantes del pueblo, causando enfermedades de las personas y animales, la infertilidad o sequias. Después del velorio, los q'eros cavan un hoyo en el cementerio, donde arrojan coca, cigarrillos y alcohol, y otros artículos que serán necesarios por los fallecidos durante su viaje. En la mandíbula de una llama esconden la comida favorita del difunto (llama lleva su comida y va con él en el viaje al volcán o apu). Los q'eros enfatiza: „Primero la gente llora, pero después alguien tiene que decir un chiste, una broma, para hacer reír a la familia, para que todos salgan alegres de la casa, para despedir alegres al alma. Es nuestra costumbre". El cuerpo del fallecido se envuelve en un lienzo y se coloca directamente en la tumba, cubriéndolo con piedras. Después del entierro, el luto continúa. La familia y todos los aldeanos se reúnen, bebiendo y comiendo. Los dolientes se consuelan, llorando y recordando a su familiar. Parece que cuando el fallecido todavía estaba en casa, durante el velatorio o transporte corporal, la presencia del fallecido todavía se sentía como si aún estuviera vivo. Diego Irarrázaval (1995:540) escribe que las comunidades andinas tratan a los fallecidos antes del entierro como a una persona viva, es como un „vivo muerto”. Cáceres Chalco (2001: 192) escribe que, en la cultura andina, como una cultura oral y visual, cuando la familia todavía ve el cuerpo del fallecido, se lo considera presente y vivo y por lo tanto no se siente intensidad de dolor. Esto ocurre cuando los parientes pierden de vista a su familiar y se dan cuenta de que ya no podrán verlo nunca más. Por lo tanto, el entierro es el momento en que el difunto finalmente deja la vida de la comunidad y la familia. Después de 2 días de entierro, es necesario lavar a fondo la ropa del difunto en el río para deshacerse de los restos de la persona fallecida e impedir el regreso de su „alma”. Con el ritual de lavar la ropa de los difuntos, un elemento muy importante es el tabaco, que debe ser fumado para asustar a qhayqasqa o 'aliento del difunto'. Si se realizan todas las ceremonias fúnebres, después de 8 días el muerto comienza a vagar hacia el apus. La descripción de las prácticas funerarias dirige una vez más nuestra atención hacia el concepto de una persona inestable y divisible. El alma del difunto busca sus restos y los recoge para que pueda entrar en el mundo de los muertos en su forma completa. La familia lava la ropa del fallecido para deshacerse de sus restos. Esto significa que el cuerpo humano se dispersa durante la vida por la ruptura de partículas pequeñas 
(uñas, cabello, epidermis, olor etc.). Todos estos elementos deben completarse para poder cerrar el ciclo de vida en el mundo vivo e iniciar una nueva etapa en el mundo de los muertos.

¿Cuáles son las relaciones entre los vivos y los muertos? Los q’eros creen que los vivos no pierden completamente el contacto con las personas fallecidas. En los q'eros hay muchas historias que describen encuentros con los muertos (almas). Según ello mejor no salir de la cabaña por la noche, y si hay que hacerlo se debe cantar, silbar o encender tabaco. De hecho, al anochecer, a menudo oía a gente regresando de montañas o campos de noche cantando o silbando. Caminando en silencio existe el peligro de colisionar con el alma del difunto, que camina por los mismos caminos que los vivos. Silbando o quemando tabaco, el alma del difunto siente la presencia de otras personas y huye. Además, cada año, el 1 de noviembre, durante Almata Mañasqa (pidiendo a los muertos), los muertos vienen durante 24 horas a visitar a sus parientes vivos. Aunque esta festividad coincide con el Día de Muertos, no está directamente relacionada con las creencias cristianas. Esta fiesta fue descrita en textos antiguos andinos - "El Manuscrito de Huarochirî" o en „La nueva crónica” de Guaman de Poma (1980[1613]). Xavier Albó (2007: 143) considera que estas creencias son de origen andino precolombino, no son el resultado del proceso de evangelización, y la convergencia de fechas es casual. Probablemente las celebraciones precolombinas de los muertos eran asociadas con la celebración del final de la estación seca y el comienzo de la temporada de lluvias. Durante Almata Mañasqa los q'eros celebran la llegada de mosoq almas (nuevos muertos). Ese día las familias comen, beben y mastican hojas de coca acompañados por los muertos quienes se alimentan como si siguieran siendo las personas vivas. Por esta razón los familiares les preparan sus comidas favoritas.

Los muertos también se comunican con los vivos a través de los sueños, en los que les transmitan mensajes, peticiones, advertencias o consejos. Hay que enfatizar que hay una relación constante entre los vivos y el mundo muerto. Según los q'eros, las almas tienen las mismas necesidades y llevan una vida similar a la de un ser humano: comen, beber, trabajan, cultivan la tierra y pastean los animales. Por esta razón, es importante cuidar a los muertos proporcionándolos alimentos (las ofrendas), como una forma de mantener la relación de reciprocidad entre las personas y los muertos. Esto suele hacerse una vez al año, sólo en noviembre. A veces, cuando los muertos dan señales - por ejemplo, aparecen en los sueños de sus familiares - los q'eros saben que necesitan preparar una ofrenda adicional. Si llueve en el Día de Muertos, significa que las almas de los muertos sufren del olvido, expresando así dolor y tristeza hacia la familia que ha dejado de cuidar de ellos - razón por la cual vienen ese día, llorando y lamentando (la lluvia se entiende aquí como el lloro de los muertos). Las celebraciones del Día de Muertos (compartiendo la misma comida) son un gesto que debemos entender como cercanía y solidaridad, y que tienen como objetivo restaurar y actualizar las relaciones de reciprocidad que unen a los muertos y a los vivos. Con el tiempo, cuando la familia de los fallecidos cesa 
las prácticas de sacrificio, los mosoq almas se convierten lentamente en machulas y con eso entran en el olvido. Los muertos, que han sido olvidados, circulan a veces por los campos en forma de machu wayra (viento de los muertos), causando enfermedades tanto en humanos como en animales. Por lo tanto, es importante mantener relaciones positivas con ellos basadas en el principio de reciprocidad (ayni). El incumplimiento de los deberes funerarios o los deberes de ofrendas a los muertos puede tener graves consecuencias para los vivos: infertilidad, enfermedades, muerte. Los muertos a cambio de sacrificios anuales ayudan a sus parientes a proteger sus cultivos y animales.

\section{Conclusiones finales}

Sobre la base del análisis de las narraciones y las observaciones de las prácticas rituales, se puede concluir que el cuerpo humano en los q'eros se entiende como una estructura permeable que registra un cambio constantemente. El cuerpo en ontología andina no es una estructura cerrada, sino un espacio que se actualiza continuamente aumentando o reduciendo las sustancias constituyentes en contacto con otros seres personales. Además de la inestabilidad y permeabilidad del cuerpo, el concepto de persona revela las características de individualidad y dividualidad que se manifiesta a través de los animu y samay, que, aunque similares, son una emanación de dos sustancias corporales diferentes. Cabe destacar que el animu no es una sustancia divisible. Su pérdida se asocia con la enfermedad, y si no se recupera conduce a una muerte inevitable. Esto nos lleva a la conclusión de que la circulación del animu entre diferentes seres no es posible. Además, esta sustancia contiene las características materiales (doble, sombra, segunda piel) - que se revela a través de cierta forma o tamaño. El samay, por otro lado, se manifiesta al comunicarse entre seres personales y durante las ofrendas rituales. Puede acumularse y perderse, lo que significa que circula no sólo en el cuerpo humano, sino también en el universo. El samay da vida al mundo, se revela en movimiento y acción. En otras palabras, samay es dividual. El animu, a su vez, tiene las características de una sustancia individual, que se enfatiza por el hecho de que afecta a tales propiedades del individuo como habilidades y carácter. En el contexto andino, la dividualidad no se limita solamente a dones o conocimientos que se transmiten entre las personas, sino que tiene una dimensión estrictamente corporal. Mientras que la persona occidental también es dividual (creada por las relaciones), su integridad corporal es mucho más marcada que de la persona andina. La transferencia de sustancias corporales se produce en pocas situaciones como la transfusión de sangre, el trasplante de órganos o la procreación, aunque para los dos primeros ejemplos, la relación entre donante y receptor no es personal ni directa (Fowler 2004:60).

El concepto del cuerpo y persona también manifiesta la relación de reciprocidad entre los diferentes seres entre los que se produce la circulación constante 
de sustancias. El hombre y todos los demás elementos del universo son construidos por las mismas sustancias, y su existencia se basa en la relación de intercambio (reciprocidad) que es necesaria para la reproducción. Los conceptos del cuerpo del individuo y del cuerpo colectivo, la Otredad y la familiaridad son la línea de mi investigación y sobre la relación entre los diferentes seres personales (humanos y no humanos) que juntos forman todo el universo animado. En este contexto, los humanos (runakuna) y los no-humanos están unidos por un complejo sistema de dependencias y obligaciones, órdenes y prohibiciones. El resultado de estas complejas relaciones entre las personas humanas y no-humanos puede ser positivo, lo que en última instancia conducirá al bienestar del individuo y de la comunidad. También puede ser negativo (predación), lo que conduce a enfermedades o muerte de seres humanos, cultivos y animales y muchas otras consecuencias trágicas. La sinergia de dos elementos opuestos pero complementarios (humanos y no humanos) es esencial para la reproducción social y la duración del universo.

\section{Notas}

1 Este texto se basa en estudios etnográficos realizados como parte del proyecto de subvención (no 2014/1S/N/HS3/01694) titulado «Ontología andina en términos antropológicos» Estudios sobre el concepto indígena de la relación „hombre-naturaleza” en el ejemplo de la comunidad quechuahablante de los q'eros, Perú." El proyecto fue financiado por el Centro Nacional de Ciencias en Cracovia y fue realizado entre 2015 y 2018.

2 El concepto de dividuo también se ha utilizado para describir la ontología de las comunidades amazónicas, que están estrechamente relacionadas con las relaciones entre humanos y no-humanos (Viveiros de Castro 2001, Vilaça 2005, 2011). Mientras que, en el contexto melanesio, una persona es formada por varias personas (multiply-authored), en el Amazonas la persona es dividual en el sentido de que está compuesta por elementos humanos y no-humanos (animales).

3 La individualización de la persona occidental es el resultado del desarrollo histórico gradual de las condiciones socioeconómicas de división social y especialización del trabajo, lo cual significa la negación de la sociedad igualitaria (Hernando 2010). Este proceso implica el desprendimiento del sujeto del mundo que lo rodea como resultado de la dominación tecnológica del hombre sobre la naturaleza, lo que ha llevado a la percepción de la naturaleza como impersonal y a la pérdida de relaciones personales con ella (Elias 1991:140).

4 La división en visible e invisible es un intento de escapar de la oposición binaria material-inmaterial. Algunas sustancias invisibles son difíciles de describir inequívocamente - son tanto tangibles como intangibles.

5 El término animu fue incorporado por los quechuas del español probablemente debido a los misioneros jesuitas.

6 La relación de intercambio entre humanos y no-humanos se analiza en detalle en mi tesis doctoral (Przytomska-La Civita 2021, en curso).

7 La división en caliente y frío no sólo se refiere a las diferencias de temperatura, sino también a las características de la naturaleza y el hombre (Yáñez del Pozo 2005:17). El tratamiento se basa en la red de la oposición, con el fin de restaurar un estado de equilibrio. Es decir, para el tratamiento de enfermedades „calientes”, se utiliza la terapia „fría” y viceversa.

8 El término servinakuy es una combinación de la palabra española 'servir' y el morfema quechua -nakuy que indica reciprocidad. En este sentido, el matrimonio significa servirse uno a otro. En cambio, el término uywanakuy significa el cuidado mutuo o la adopción mutuo.

9 De hecho, Josef Estermann (1998) fue el primero en utilizar el término analogía en relación con la ontología andina, no Descola (2013), como se cree comúnmente. Para describir la ontología análoga, Descola utiliza el ejemplo de la cosmología de los nahuas de México central, que fue descrito por el historiador mexicano Alfredo López Austin (1988) en el libro „El cuerpo humano y la ide- 
ología: conceptos de los antiguos nahuas". La obra de López Austin se basa en un análisis filológico de fuentes en lengua náhuatl, sobre un análisis crítico de materiales etnográficos españoles del siglo XVI, en particular la obra de la Historia General de las Cosas de la Nueva España por el franciscano Bernardino de Sahagún; y las obras etnográficas de nahuas modernos.

10 Warmintin qharintinpuni! - es decir, „Mujeres y hombres siempre juntos”. Este es un comentario de un interlocutor de Holly Wissler (2009:45) acerca de los papeles musicales en q'eros taki, durante el cual las mujeres cantan y los hombres tocan el pinkuyllu (flauta andina). En este contexto, el hombre y la mujer actuan juntos y forman una totalidad conjunta. Nunca se interpreta una canción sin acompañamiento de flauta.

\section{Referencias citadas}

Allen, Catherine

2008 La coca sabe: coca e identidad cultural en una comunidad andina. 372 pp. Centro Bartolome de las Casas, Cusco.

2016 The Living Ones: Miniatures and Animation in the Andes. Journal of

Bastien, Joseph anthropological research 72 (4): 416-41.

1985 Qollahuaya-Andean Body Concepts: A Topographical-Hydraulic Model of Physiology. American Anthropologist 87 (3): 595-611.

Battaglia, Debbora

1995 Problematizing the self: a thematic introduction'. En Rhetorics of Selfmaking, Editado por Debbora Battaglia. pp. 1-15. University of California Press, Berkeley:

Bolin, Inge

2006 Growing Up in a Culture of Respect: Child Rearing in Highland Peru. 214 pp. University of Texas Press, Austin.

Bolton, Ralph

1976 Andean Coca Chewing: A Metabolic Perspective, American Anthropo-

Boyer, Isabel Neila

logist 78: 630-634.

2006 El samay, el "susto" y el concepto de la persona en Ayacucho. En Salud e interculturalidad en América latina: antropología de la saludy crítica intercultural, editado por Gerardo Fernández Juárez. pp. 187216, Abya Yala, Quito.

Burgos, Maria Ofelia

$1995 \quad$ El ritual del parto en los Andes: aspectos socio-culturales de la concepción, embarazo, parto, puerperio, recién nacido y parteras tradicionales en la zona sur-andina del Perú, tesis doctoral, Nijmegen : Katholieke Universiteit Nijmegen, Derde Wereld Centrum, Ontwikkelingsstudies.

Cáceres Chalco, Efraín

2001 La muerte como sanación y compensación: visión de equilibrio y reciprocidad en Cusco. Chungará 33 (2): 187-200. 
de la Cadena, Marisol

2015 Earth Beings. Ecologies of Practice Across Andean Worlds. 340 pp. Duke University Press, Durham.

Carranza Romero, Francisco

2005 El mundo de los muertos en la concepción quechua. Ciberayllu [en línea]

http://www.andes.missouri.edu/andes/Especiales/FCR_Muertos.html> (consulta: 12 de agosto del 2018).

Carrithers, Michael, Collins, Steven y Lukes, Steven (editores)

1985 The Category of the Person: Anthropology, Philosophy, History. 320 pp. Cambridge University Press, Cambridge.

Carter, Wiliam y Mamani, Mauricio

1982 Irpa Chico Individuo y Comunidad en la Cultura Aymara, 460 pp. Juventud, La Paz.

Celestino, Olinda

1997 Transformaciones religiosas en los Andes peruanos. 1. Ciclos míticos y rituales, Gazeta de Antropologia 13 (6) [en línea]

https://www.ugr.es/ pwlac/G13_06Olinda_Celestino.html

Descola, Phillipe

2013 Beyond nature and culture, pp. 462. University of Chicago Press, Chicago.

Dehouve, Danièle

2015 Metáforas y metonimias conceptuales en las representacioness antropomórficas del maíz. En Múltiples formas de ser nahua. Representaciones, conceptos y prácticas en el siglo XXI, editado por Catherine Good Eshelman and Dominique Raby, pp. 37-57, El Colegio de Michoacán, Michoacán, Mexico.

2016 El depósito ritual. Una práctica mesoamericana de larga duración, Confluenze 8 (2): 181-206.

Elias, Norbert

1991 The Society of Individuals. 264pp. Basil Blackwell, Oxford.

Estermann, Josef

$1998 \quad$ Filosofía Andina. Estudio intercultural de la sabiduría autóctona andi-

Fourtané, Nicole na. 359 pp. Ediciones Abya - Yala, Ecuador.

2015 El condenado andino. Estudios de cuentos peruanos. 269 pp. IFEA, CBC, Lima, Cusco.

Fowler, Chris

2004 The archaeology of personhood. An anthropological approach, $196 \mathrm{pp}$. Routledge, London, New York. 
Greenway, Christine

1998a Hungry earth and vengeful stars: soul loss and identity in Peruvian Andes. Soc. Sci. Med 48 (8): 993-1004.

Gell, Alfred

1993 Wrapping in Images: Tattooing in Polynesia. 360 pp. Clarendon, Oxford

1998 Art and agency: An anthropological theory. 271 pp. Oxford University Press, Oxford

González Holguín, Diego

1989 [1608] Vocabulario de la lengua general de todo el Perú llamada lengua quichua o del Inca. 707 pp. Universidad Nacional Mayor de San Marcos, Lima.

Guamán Poma de Ayala, Felipe

1980 [1613] El primer Nueva Crónica y Buen gobierno, 1176 pp. Siglo XXI Editores, México.

Harrison, Regina

1989 Signs, Songs and Memory in the Andes: Translating Quechua Language and Culture. 233 pp. University of Texas Press, Austin.

Hernando, Almudena

2010 Gender, Individualization, and Affine/Consanguineal. Relationships. En "Egalitarian Societies": The Awá-Guajá Case, editado por L.H. Dommasnes, T. Hjørungdal, S. Montón-Subías, M. Sánchez Romero, and N.L. Wicker (eds.). pp. 283-306. Archaeolingua, Budapest.

Huby, Manuel

1954 Algunas observaciones del Folklore médico del departamento de Junín Inglod, Tim en Perú. Indígena (5): 13 70-91, Lima.

2000 The Perception of the Environment: Essays in Livelihood, Dwelling and Skill, 480 pp. Routledge, London.

Irarrázaval, Diego

1994 Arte de Muerte y Vida, Allpanchis 43/44: 529-558.

LiPuma, E.

1998 Modernity and forms of personhood in Melanesia. En Bodies and Persons: Comparative Views from Africa and Melanesia, editado por Michael Lambek and Andrew Strathern (eds) pp. 53-79, Cambridge University Press, Cambridge.

La Riva González, Palmira

2005 Las representaciones del animu en los Andes del sur peruano. Revista Andina 41:63-86.

2013 Watuchi. Enigmas y saberes infantiles en los Andes del sur del Perú, Bulletin de l'Institut Français d'Études Andines 42 (3): 369-388. 
López Austin, Alfredo.

1988 The Human Body and Ideology: Concepts of the Ancient Nahuas. 315 pp. University of Utah Press, Salt Lake City.

Llanos Cervantes, Elvira

El embarazo en mujeres aymaras migrantes. Un estudio en zonas urbanas populares al oeste de La Paz, En Mujeres de los Andes: Condiciones de vida y salud, editado por Anne-Claire Defossez et al. pp. 114-140, Institut français d'études andines, Lima.

Marriott, McKim

1976 Hindu transactions: diversity without dualism, En Transaction and Meaning, editado por Bruce Kapferer, ISHI Publications (ASA Essays in Anthropology 1), Philadelphia.

Martinez, Joaquin y Mari, Odena

1976 Matrimonio y familia en Bolivia. Estudio comparativo del matrimonio y vida de familia en el altiplano, los valles y el trópico. 272 pp. Los Amigos del Libro, La Paz-Cochabamba.

Molinié Fioravanti, Antoinette

1991 El Pishtaco: Presentación. Bulletin de l'Institut Francais d'Éstudes Andines 20 (1): 1-2.

Mosko, Mark y Damon, Fred

2005 On the Order of Chaos: Social Anthropology and the Science of Chaos. 296 pp. Berghahn Books, New York, Oxford.

Murray, D.W

1993 What is the Western conception of the self? On forgetting David Hume. Ethos 21 (1): 3-23.

Nash, George

1998 Exchange, Status and Mobility: Mesolithic Portable Art of Southern Scandinavia, pp 192. BAR International Series 710, Oxford.

Platt, Tristan

1986 Mirrors and Maize. The Concept of Yanantin Among the Macha of Bolivia. En Anthropological History of Andean Polities, editado por John Murra, Nathan Wachtel y Jacques Revel, pp. 229-259, Cambridge University Press, Cambridge.

Przytomska-La Civita, Anna

$2021 \quad$ Ludzie i nie-ludzie: ontologia andyjska w ujęciu antropologicznym na przykładzie keczuańskiej społeczności Q'eros z Peru, tesis doctoral, Universidad de Adam Mickiewicz, Poznań (en curso).

Rasmussen, S.

1995 Spirit Possession and Personhood Among the Kel Ewey Tuareg, 196 pp. Cambridge University Press, Cambridge. 
Ricard Lanata, Xavier

2007 Ladrones de sombra: El universo religioso de los pastores del Ausangate (Andes surperuanos). 636 pp. Institut français d'études andines, Lima.

Riches, David

1995 Dreaming as Social Process, and its Implications for Consciousness, En Questions of Consciousness, editado por Anthony Cohen and Nigel Rapport, p. 101-117, Routledge, Londres y Nueva York.

Rivera Palomino, Juan

1994 Concepción de la naturaleza en el mundo occidental y en el mundo Salomon, Frank andino-amazónico. Logos Latinoamericano II (2): 26-37.

1991 Introduction, En The Huarochirí manuscript, editado y traducido por Frank Salomon and George Urioste, pp.1-38, University of Texas Press, Austin.

Sánchez-Parga, José

1985 La bebida en los Andes ecuatorianos: ritualidad y control social. Cultura 21(31): 5-38.

Santa María, Luis Alberto

2017 Salud intercultural: el ciclo vital en los andes, Revista Peruana de Medicina Experimental y Salud Publica 34 (2): 293-298.

Schlegelberger, Bruno

1993 La Tierra Vive: Religión Agraria y Cristianismo en los Andes Centrales Peruanos. 549 pp. CAIJO, Cusco.

Silverblatt, Irene

1987 Moon, Sun, and Witches, Gender ldeologies and Class in Inca and Colonial Peru. Pp. 302. Princeton University Press, Princeton.

Strathern, Marilyn

$1988 \quad$ The gender of the gift: Problems with women and problems with society in Melanesia. 437 pp. University of California Press, Berkeley.

2004 Partial Connections. 153 pp. Altamira, Nueva York.

Torres Lezama, Vicente

2017 Cuerpo, animu y alma como integridad en la persona andina, En $R e$ cuperando la vida. Etnografías de sanación en Perú y México, editado por Vicente Torres Lezama, Victor Anguiano, pp. 33-74, Ríos profundos, Lima.

Urton, Gary

2003 Signs of the Inka Khipu. 208 pp. University of Texas Press, Austin.

Valderrama, Ricardo y Escalante, Carmen

2012 Montañas sagradas y rituales en los andes. En Cultura Andina. Cosmovisión, arqueología, editado por Jesús W. Rozas y Delmia Valencia, pp. 19-50, UNSAAC, CIUF y Atoq editores, Cusco - Perú. 
Valencia Espinoza, Abraham

2013 El Paulucha: Personaje mitológico quechua. Revista Patrimonio 6, Ministerio de Cultura/DRCC Editores, Cusco.

Valiente, Teresa

1979 Der Lebenszyklus inkaischer Zeit und Quechua Dorfgemeischaften der Gegenwart, tesis doctoral. Berlin.

Vilaça, Aparecida

2002 Making kin out of others. Journal of the Royal Anthropological Institute 8:347-65.

2005 Chronically unstable bodies: Reflections on Amazonian corporalities. Journal of the Royal Anthropological Institute (N.S.) 11 (3): 445-64.

2011 Dividuality in Amazonia: God, the devil and the constitution of personhood in Wari' Christianity. Journal of the Royal Anthropological Institute (N.S.) 17 (2): 243-62.

Viveiros de Castro, Eduardo

2001 GUT feelings about Amazonia: Potential affinity and the construction of sociality. En Beyond the visible and the material: The Amerindianization of society in the work of Peter Rivière, editado por Laura M. Rival y Neil L. Whitehead, pp. 19-43, Oxford University Press, Oxford.

Wagner, Catherine

1976 Coca y estructura cultural en los andes peruanos. Allpanchis 8(9), 193223.

Webb, Hillary

2012 Yanantin and masintin in the Andean world: Complementary dualism in modern Peru. 192 pp. University of New Mexico Press, Albuquerque.

Willerslev, Rane

2007 Soul Hunters: Hunting, Animism, and Personhood among the Siberian Yukaghirs. 229 pp. University of California Press, Berkeley.

Wissler, Holly

2009 From Grief and Joy We Sing: Social and Cosmic Regenerative Processes in the Songs of Q'eros, Peru, tesis doctoral, Florida State University. https://fsu.digital.flvc.org/islandora/object/fsu\%3A169148

Wörrle, Bernhard

1999 De la cocina a la brujería. La sal entre los indígenas y mestizos en América Latina. 260 pp. Abya-Yala, Quito.

Yánez del Pozo, José

2005 Allikai: bienestar/estar bien la salud y la enfermedad desde la perspectiva indígena. 90 pp. Quito: Abya-Yala. 
192 Anna Przytomska-La Civita

Zuidema, Tom

1989 The Moieties of Cuzco. En The Attraction of Opposites. Thought and Society In the Dualist Mode, editado por David Mybury-Lewis y Uri Almagor. pp. 255-75, University of Michigan Press, Ann Arbor. 